\title{
Protecting Our Elderly Patients from Adverse Drug Reactions
}

\author{
Glen Brown
}

$\mathrm{E}$ xperience with pharmaceutical care and findings in the iterature have demonstrated that older patients are at greater risk for adverse drug reactions (ADRs) than are younger populations. In this issue, Mihajlovic and others ${ }^{1}$ add to this knowledge through a systematic review of patient characteristics that appear to place individual patients at risk for ADRs. Their intent was to assist pharmacists in identifying those patients at higher risk for an $\mathrm{ADR}$ within a general population receiving care from individual pharmacists, and therefore, to more efficiently direct the pharmacists' activities to where they potentially will have greater benefit. So how do we now use this information when triaging a large case load?

Over the past 5 years, several investigator groups have attempted to create, validate, and implement screening mechanisms to identify the elderly patients most likely to benefit from interventions to reduce the risk of ADRs. The most widely recognized strategy uses the Beers criteria, a listing of drugs that carry a high risk of being inappropriate for elderly patients. ${ }^{2}$ As one example, Quebec-based pharmacists demonstrated that a computerized review of individual patients' health care records using selected Beers criteria could identify patients for whom inappropriate medications had been prescribed. ${ }^{3}$ In that study, computerization of patient screening allowed the pharmacists to efficiently identify patients at risk of ADRs and intervene to adjust their therapy.

Pharmacists practising in emergency departments have been shown to reduce the prescribing of inappropriate therapies, as defined by the Beers criteria, by educating prescribers, by developing notices for patient-drug combinations to be avoided that can be implemented via computerized prescriber order entry, and by giving feedback to prescribers on their performance. ${ }^{4}$ These steps could be thought of as similar to the feedback and intervention techniques employed by antimicrobial stewardship programs. Previously in the Canadian Journal of Hospital Pharmacy, Slaney and others 5 showed that application of the Beers criteria identified elderly patients needing an alternate level of care (long-term care) who subsequently experienced an ADR. These results suggest that screening elderly patients for prescribing of inappropriate medications, as defined by the Beers criteria, would assist the pharmacist in triaging to ensure that those in most need receive attention.

Other investigators have used the evidence-based STOPP/START (Screening Tool of Older Person's Prescriptions/ Screening Tool to Alert doctors to Right Treatment) criteria to identify patients needing evaluation of their drug therapy. ${ }^{6}$ These tools list 81 specific drug-disease-patient scenarios that should lead to consideration of discontinuation of prescribed therapy, and 34 drug-disease-patient scenarios where drug therapy should be initiated. Although this may sound like a complex and laborious process, all of the recommended scenarios are easily understandable and identifiable by practising pharmacists. Application of the STOPP/START screening criteria has been shown to improve the appropriateness of prescribing ${ }^{7}$ and reduce subsequent drug-related readmissions. ${ }^{8}$ Investigators in Nova Scotia found that the STOPP/START screening tools were potentially more effective than the Beers criteria in identifying drug therapy that would put elderly patients at risk for an ADR, and their use may have measurable benefits in terms of subsequent patient well-being and health resource utilization. ${ }^{9,10}$

Other researchers have shown that pharmacists can improve prescribing $^{11}$ and reduce subsequent $A D R s^{12}$ when they use a structured approach to identifying and interviewing patients with a view to assessing their drug therapy. In these studies, the pharmacists were assisted by computerized decision support software that utilized the assessment tools described above, evaluation of current laboratory data, and reconciliation of the patients' past and current therapy. They found that application of this method prevented 1 ADR for every 14 patients assessed. ${ }^{12}$ Use of a frailty index to identify those elderly individuals at greatest risk for ADRs may further assist the pharmacist in the triage process. ${ }^{13} \mathrm{~A}$ simple assessment score based on only 5 clinical variables $(>8$ medications, hyperlipidemia, elevated white blood cell count, use 
of antidiabetic agents, and hospital length of stay $>12$ days) has been validated for predicting which of the very old (i.e., $>80$ years of age) are likely to experience an ADR. ${ }^{14}$

Research showing that our elderly patients are at heightened risk for ADRs, including the study by Mihajlovic and others, ${ }^{1}$ coupled with the proven benefit of the screening and intervention techniques described above, should encourage all Canadian institutional pharmacists to implement methods for identifying these vulnerable patients and then to intervene. Individual pharmacists and, particularly, clinical pharmacy administrators should look at the organization of their pharmaceutical care programs or services to determine how screening techniques could be used to identify those elderly patients with greater need for pharmacists' attention than the general population. Utilization of computer resources, including distribution systems, patient information systems, and electronic health care records, to efficiently screen for patients on the basis of proven beneficial criteria would have the greatest impact at the lowest cost in terms of pharmacists' time. Our elderly patients need this care ... it's time to act!

\section{References}

1. Mihajlovic S, Gauthier J, MacDonald E. Patient characteristics associated with adverse drug events in hospital: an overview of reviews. Can J Hosp Pharm. 2016;69(4):294-300.

2. American Geriatric Society 2012 Beers Criteria Update Expert Panel. American Geriatric Society updated Beers criteria for potentially inappropriate medication use in older adults. J Am Geriatr Soc. 2012;60(4):616-31.

3. Arvisais K, Bergeron-Wolff S, Bouffard C, Michaud AS, Bergeron J, Mallet $\mathrm{L}$, et al. A pharmacist-physician intervention model using a computerized alert system to reduce high-risk medication use in elderly inpatients. Drugs Ageing. 2015;32(8):663-70.

4. Moss JM, Bryan WE 3rd, Wilkerson LM, Jackson GL, Owenby RK, Van Houtven C, et al. Impact of clinical pharmacy specialists on the design and implementation of a quality improvement initiative to decrease inappropriate medications in a Veterans Affairs emergency department. J Manag Care Spec Pharm. 2016;22(1):74-80.

5. Slaney H, MacAulay S, Irvine-Meek J, Murray J. Application of the Beers criteria to alternate level of care patients in hospital inpatient units. Can J Hosp Pharm. 2015;68(3):218-25.

6. O’Mahony D, O’Sullivan D, Byrne S, O'Connor MN, Ryan C, Gallagher P. STOPP/START criteria for potentially inappropriate prescribing in older people: version 2. Age Ageing. 2015;44(2):213-8.
7. Gallagher PF, O'Connor MN, O'Mahony D. Prevention of potentially inappropriate prescribing for elderly patients: a randomized controlled trial using STOPP/START criteria. Clin Pharmacol Ther. 2011;89(6):845-54.

8. Gillespie U, Alassaad A, Hammarlund-Udenaes M, Mörlin C, Henrohn D, Bertilsson $\mathrm{M}$, et al. Effects of pharmacists' interventions on appropriateness of prescribing and evaluation of the instruments' (MAI, STOPP and STARTs') ability to predict hospitalization-analyses from a randomized controlled trial. PLoS One. 2013;8(5):e62401.

9. Hill-Taylor B, Sketris I, Hayden J, Byrne S, O'Sullivan D, Christie R. Application of the STOPP/START criteria: a systematic review of the prevalence of potentially inappropriate prescribing in older adults, and evidence of clinical, humanistic and economic impact. J Clin Pharm Ther. 2013;38(5):360-72.

10. Hill-Taylor B, Walsh KA, Stewart S, Hayden J, Byrne S, Sketris IS, Effectiveness of the STOPP/START (Screening Tool of Older Persons' potentially inappropriate Prescribing/Screening Tool to Alert doctors to the Right Treatment) criteria: systematic review and meta-analysis of randomized controlled studies. J Clin Pharm Ther. 2016;41(2):158-69.

11. O'Sullivan D, O’Mahony D, O'Connor MN, Gallagher P, Cullinan S, O'Sullivan R, et al. The impact of a structured pharmacist intervention on the appropriateness of prescribing in older hospitalized patients. Drugs Aging. 2014;31(6):471-81.

12. O'Sullivan D, O'Mahony D, O'Connor MN, Gallagher P, Gallagher J, Cullinan S, et al. Prevention of adverse drug reactions in hospitalised older patients using a software-supported structured pharmacist intervention: a cluster randomized controlled trial. Drugs Aging. 2016;33(1):63-73.

13. Cullinan S, O'Mahony D, O'Sullivan D, Byrne S. Use of a frailty index to identify potentially inappropriate prescribing and adverse drug reaction risks in older patients. Age Ageing. 2016;45(1):115-20.

14. Tangiisuran B, Scutt G, Stevenson J, Wright J, Onder G, Petrovic M, et al. Development and validation of a risk model for predicting adverse drug reactions in older people during hospital stay: Brighton Adverse Drug Reactions Risk (BADRI) Model. PloS One. 2014;9(10):e111254.

Glen Brown, PharmD, FCSHP, BCPS(AQ), BCCCP, is with the Pharmacy, St Paul's Hospital, Vancouver, British Columbia. He is also an Associate Editor with the Canadian Journal of Hospital Pharmacy.

Competing interests: None declared.

\section{Address correspondence to:}

Dr Glen Brown

Pharmacy

St Paul's Hospital

1081 Burrard Street

Vancouver BC V6Z 1Y6

e-mail: gbrown@providencehealth.bc.ca 